\title{
Effect of 8-week oral supplementation with 3- $\mu$ g cyano-B12 or hydroxo-B12 in a vitamin B12-deficient population
}

\author{
Eva Greibe $^{1}$ (D) Namita Mahalle ${ }^{2} \cdot$ Vijayshri Bhide $^{2} \cdot$ Sergey Fedosov $^{3} \cdot$ Christian W. Heegaard $^{3} \cdot$ Sadanand Naik $^{2}$. \\ Ebba Nexo ${ }^{1}$
}

Received: 3 July 2017 / Accepted: 29 November 2017 / Published online: 5 December 2017

(c) The Author(s) 2017. This article is an open access publication

\begin{abstract}
Purpose We compare the effect of 8-week oral supplementation with cyano-B12 (currently used in vitamin pills) and hydroxo-B12 (predominant form in the diet) in a population with nutritional vitamin B12 deficiency.

Methods Fifty-one healthy Indian adults with baseline serum cobalamin $<200 \mathrm{pmol} / \mathrm{L}$ were supplied for 8 weeks with daily oral supplements of 3- $\mu$ g cyano-B12 $(n=15), 3-\mu \mathrm{g}$ hydroxo-B12 $(n=16)$, or a placebo $(n=20)$. Blood at baseline, and each following week, was examined for total cobalamin, holotranscobalamin, methylmalonic acid, and homocysteine.

Results The study groups did not differ at baseline and were characterized by [median (range)] serum cobalamin [128 (68-191) pmol/L], holotranscobalamin [16 (6-41) pmol/L], methylmalonic acid [0.8 (0.3-1.7) $\mu \mathrm{mol} / \mathrm{L}]$, homocysteine [17.9 $(8.5-100.9) \mu \mathrm{mol} / \mathrm{L}]$, and a combined indicator of B12 status $4 \mathrm{cB} 12$ of -1.65 ( -0.64 to -4.07$)$. The group supplemented with cyano-B12 showed a higher increase in total serum cobalamin than the group treated with hydroxo-B12, while other biomarkers changed comparably in the two groups. After 8 weeks of treatment, the biomarker values of the supplemented groups (pooled) differed significantly from the placebo group. Yet, the vitamin B12 status was still poor [cobalamin: 168 (87-302) pmol/L; holotranscobalamin: 19 (8-45) pmol/L; methylmalonic acid: 0.7 (0.2-1.7) $\mu$ mol/L; homocysteine: 17.2 (2.6-96.8) $\mu \mathrm{mol} / \mathrm{L} ; 4 \mathrm{cB} 12=-1.34(-0.33$ to -3.3$)]$.

Conclusion 8 -week supplementation with 3- $\mu$ g cyano-B12 elevated serum cobalamin more than $3 \mu \mathrm{g}$ hydroxo-B12, but all other biomarkers changed similarly in both groups. Supplementation with $3 \mu \mathrm{g}$ vitamin B12 did not reverse the low status in individuals with nutritional vitamin B12 deficiency.
\end{abstract}

Clinical Trial Registry of India REF/2017/02/013343.

Keywords Vitamin B12 - Cobalamin · Cyano-B12 · Hydroxo-B12 · B12 supplementation · B12 deficiency

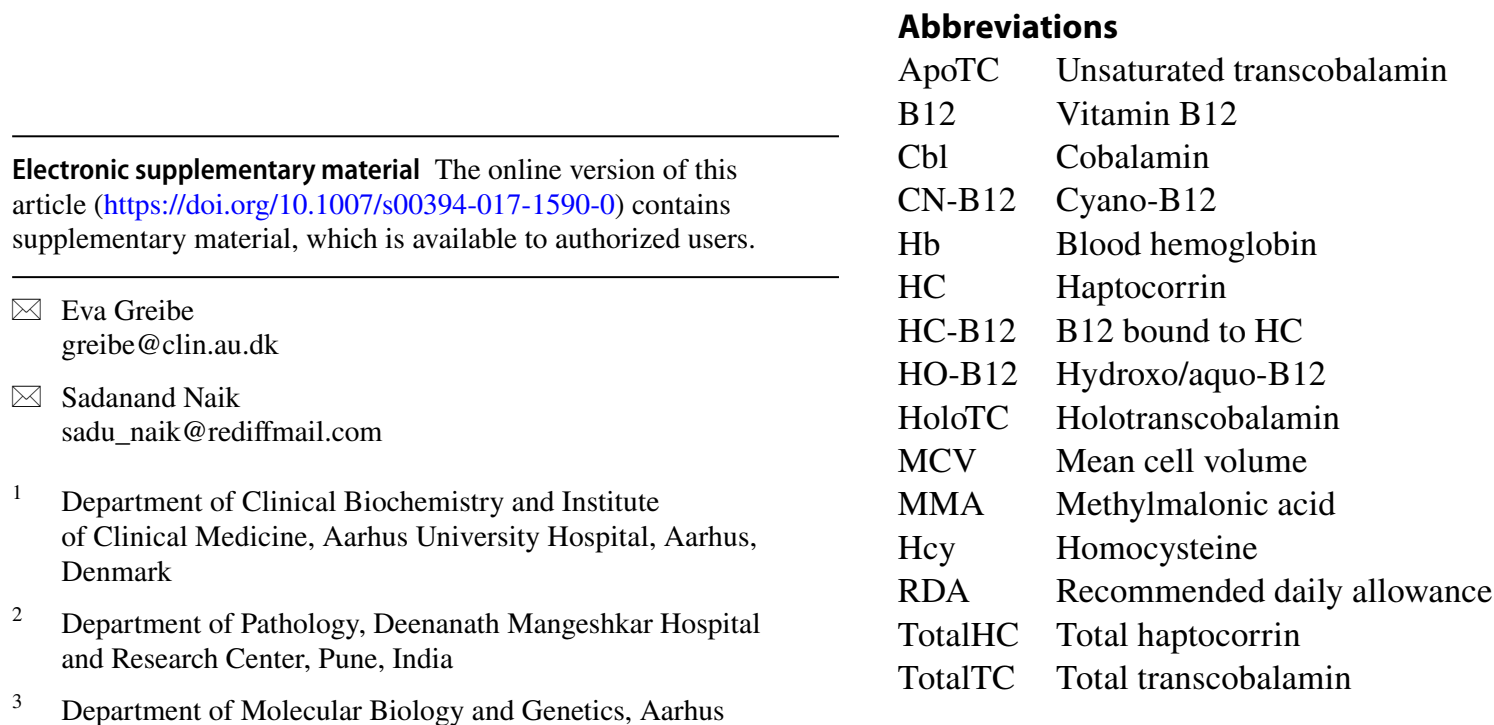




\section{Introduction}

Vitamin B12 (B12) is involved in a number of key metabolic processes including cell division and nervous system function. Deficiency may result in development of anemia and/or neurological symptoms. The vitamin is present in foods of animal origin as the coenzymes 5'-deoxyadenosyl-B12 and methyl-B12 [1] that both are converted into hydroxo-B12 (HO-B12) upon light exposure [2]. Thus, $\mathrm{HO}-\mathrm{B} 12$ is a ubiquitous and sometimes predominant form of B12 in food [1]. The daily supply of B12 in a Western omnivorous diet is around $6 \mu \mathrm{g}[3,4]$, well above the recommended daily allowance (RDA) of $2.4 \mu \mathrm{g}$ [5].

Populations of some countries-like India [6]—consume a diet containing B12 levels far below the RDA, and are, therefore, at risk of developing low B12 status and possibly overt B12 deficiency. Thus, during the last decade, there has been a growing awareness of the need for food fortification or supplementation of the diet with vitamin pills in such populations [7, 8]. Biochemically, B12 deficiency causes a decline in serum cobalamin ( $\mathrm{Cbl})$ and holotranscobalamin (holoTC); also called "active" B12, because this protein-B12 complex ensures transport of the vitamin into the cells. An increase in the metabolic markers methylmalonic acid (MMA) and/or homocysteine (Hcy) also indicates B12 deficiency. To combat this, the synthetic cyano-B12 (CN-B12) is used for supplementation purposes, because it is the least expensive vitamin form and resists aggressive chemicals better than HO-B12. Several studies have documented that both forms are retained alike after oral uptake [9-11], but the tissue distributions of the two absorbed vitamins differ. For example, in rats, considerably more B 12 is internalized in the liver after ingestion of HO-B 12, when compared to an equal dose of CN-B12 [12, 13]. Conversely, the circulating level of $\mathrm{B} 12$ is much higher upon administration of CN-B12 than after intake of similar dose of HO-B12 [11-14].

The current knowledge leaves us with two important questions: can a daily oral dose of B 12 just above the RDA repair the B12 status of individuals not receiving sufficient quantities of dietary B12? Do treatments with either CN-B12 or HO-B12 lead to different or comparable results? Here, we investigate the effect of 8 -week daily supplementation with $3 \mu \mathrm{g}$ of CN-B12 or HO-B12 on markers of the B12 status in a B12-deficient Indian population.

\section{Subjects and methods}

\section{Participants and study design}

This longitudinal cohort intervention study was designed to investigate the B12 status in nutritionally induced B12-deficient Indian individuals, supplemented for 8 weeks with one daily dose of $3-\mu \mathrm{g}$ CN-B12, 3- $\mu \mathrm{g}$ HO-B12, or no B12 (placebo). Non-fasting blood samples were drawn at baseline and each week throughout the study. Collected samples were measured for $\mathrm{Cbl}$ and related variables (see Biochemical measurements). The study was blinded, so that participants and health care staff did not know the content of the administered capsules.

Participants aged $\geq 18$ years $(n=60)(27$ males and 33 females) were recruited from the Pune area in India, and the study was carried out at Deenanath Mangeshkar Hospital and Research Center, Pune, India, in the spring of 2016. Most of the participants were healthy staff at the hospital. Inclusion criterion was a plasma Cbl below $150 \mathrm{pmol} / \mathrm{L}$ measured 2 weeks prior to enrollment. Exclusion criteria were use of vitamin pills containing $>1-\mu \mathrm{g}$ B 12 within the last 2 weeks, drugs known to influence B12 absorption, and any known chronic systemic disease. The number of participants included in the study was based on power calculations, using a multiple linear regression showing a statistical power of $90 \%(\alpha=0.05)$. The number of participants was adjusted for expected dropout due to the nature of the longitudinal design. The 60 participants were randomly divided into three groups [CN-group $(n=20)$, HOgroup $(n=20)$, and placebo group $(n=20)]$ with an equal distribution of sex and age. All participants were asked to eat their usual diet throughout the study. Most of the participants were lacto-vegetarians $(65 \%)$ and the rest were partly non-vegetarians (consuming a portion of non-vegetarian food approximately twice a week). The participants received no money for participation in the study; however, the placebo group received 8 weeks of B12 supplements (Neurobion with 15- $\mu$ g CN-B12) for compensation after the study was completed.

\section{Preparation of CN-B12 and HO-B12 capsules for oral administration}

Here and throughout the manuscript, the term HO-B12 covers both hydroxo-B12 and aquo-B12. The two forms are interchangeable, and their presence depends on the $\mathrm{pH}$ of the solution. CN-B12 and HO-B12 were given as aqueous solutions absorbed in 30-mg sugar and packed in two-piece hard-shell gelatin capsules (Natur-Drogeriet, Horning, Denmark) as described in Greibe et al. [14]. In 
brief, CN-B12 (Betolvex, A ctavis, Gentofte, Denmark) and HO-B12 (Vibeden, Sandox, Copenhagen, Denmark) were dissolved in sterile demineralized water and centrifuged at $12,000 \times g$ for $5 \mathrm{~min}$ at room temperature. The supernatants were retained, and the B 12 concentrations were adjusted to $0.25 \mathrm{mg} / \mathrm{mL}$ in sterile demineralized water. To ensure that the concentrations were accurate, six aliquots of each B12 stock were diluted 1:5 in sterile demineralized water and converted to di-CN-B12 by incubating them with $0.5-\mathrm{mL} 0.2-\mathrm{M} \mathrm{KCN}$ for $1 \mathrm{~h}$ in the dark. The absorption of di-CN-B12 at $368 \mathrm{~nm}$ was determined using a Shimadzu UV-1800 Spectrophotometer (Holm \& Halby, Broendby, Denmark), and used to calculate the B12 concentration using a molar absorption coefficient of diCN-B12 of 30,400 L/mol/cm [2]. The mean of six aliquots was used to calculate the exact stock volume needed to

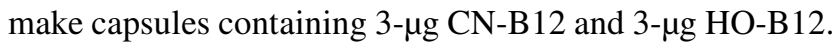
The coefficient of variation (CV\%) was $1 \%$ for the six aliquots of both CN-B12 and HO-B12. For further testing, the sugar-B12 capsules were redissolved in water and analyzed for B12 content using the Advia Centaur CP Immunoassay System (Siemens). The placebo capsules were made by packing $30-\mathrm{mg}$ sugar in gelatin capsules without the addition of B12. All capsules, with or without B12, were stored in light-protected containers at $4{ }^{\circ} \mathrm{C}$ together with a desiccant. The maximal storage time of 6 weeks did not cause any changes in the B12 content, as previously demonstrated [14].

\section{Biochemical measurements}

Blood samples were centrifuged ( $10 \mathrm{~min}$ at $2300 \times \mathrm{g}$ ) within $2 \mathrm{~h}$ of being drawn, and serum was stored at $-20^{\circ} \mathrm{C}$ for later analysis. Serum aliquots were shipped to Denmark on ice for analysis of Cbl, holoTC, total transcobalamin (totalTC), total haptocorrin (totalHC), and MMA. The samples were frozen upon arrival. Hcy and hematological parameters (see below) were analyzed on EDTA plasma in India.

For each B12-related variable, all samples from each participant were measured in one run. Serum Cbl was measured on the Advia Centaur CP Immunoassay System (Siemens). Serum holoTC was determined using in-house sandwich ELISA, after removal of unsaturated transcobalamin (apoTC) with B12-coated magnetic beads [15]. The total imprecision was 8\% [15] and the intra-assay imprecision was $4 \%$ [16]. The mean holoTC values for the low, intermediate, and high controls were 40,70 , and $114 \mathrm{pmol} / \mathrm{L}$, respectively [16]. The samples were also examined for totalTC using the above-mentioned TC ELISA. TotalHC was measured by in-house HC ELISA with a total imprecision of 5\% and the intra-assay imprecision of $2 \%$ [17]. The amount of B12 bound to $\mathrm{HC}$ (HC-B12) was calculated as total serum $\mathrm{Cbl}$ minus holoTC.
MMA was quantified by Liquid Chromatography-Tandem Mass spectrometry on the AB SCIEX Triple Quad 5500 System (AB SCIEX). Hcy was measured on the Architect Immunoassay Analyser (Abbott). Hemoglobin $(\mathrm{Hb})$ and red blood cell mean cell volume (MCV) were determined on the XN 3000 Hematology Analyzer (Sysmex), and plasma creatinine was measured on the RX Imola (Randox Laboratories), employing routine ISO certified assays. The combined indicator of B12 status, $4 \mathrm{cB} 12$, was calculated from the measurements of serum $\mathrm{Cbl}$, holoTC, MMA, and Hcy using the formula presented by Fedosov et al. [18].

\section{Statistics and data fitting}

The D'Agostino-Pearson omnibus test was used to determine if data followed the Gaussian distribution. The unpaired $t$ test (normally distributed data) or the Mann-Whitney $U$ test (not normally distributed data) was used to test for differences between the groups at individual time points, and the paired $t$ test (normally distributed data) or the Wilcoxon's signed-rank test (not normally distributed data) was used to test for differences between baseline and individual time points within the groups (Table 1; Fig. 1).

Changes in serum $\mathrm{Cbl}\left(\Delta \mathrm{Cbl}=\mathrm{Cbl}-\mathrm{Cbl}_{0}\right)$ and holoTC $\left(\Delta\right.$ holoTC $=$ holoTC - holoTC $\left.{ }_{0}\right)$ from the respective baselines $\left(X_{0}\right)$ were calculated for each patient (Fig. 2). The data were plotted over time as three data sets (CN-group, HO-group, and placebo group), and the points for each group were fitted using an exponential function. The underlying mathematics is presented in Supplementary data S1. The fitted models for each group were compared with $t$ tests.

Changes in MMA and Hcy over time were presented as ratios between the concentration at a given time point and the concentration at the baseline (e.g., MMA/MMA ${ }_{0}$ ). Difference from the baseline ( $\triangle \mathrm{MMA}$ and $\Delta \mathrm{Hcy}$ ) could not be used, because this value is proportional to the baseline concentration $\left(\mathrm{MMA}_{0}\right.$ and $\mathrm{Hcy}_{0}$ ) (see the theoretical substantiation of this statement in [23]). At a limited concentration interval, the dependence on baseline can be compensated by division (X/ $\mathrm{X}_{0}$ ). The ratios were plotted as three data sets (for $\mathrm{CN}$-group, HO-group, and placebo group) and fitted by a linear function. The underlying mathematics is presented in Supplementary data S1. The fitted models for each group were compared with $t$ tests.

Data analysis was performed using GraphPad Prism 5 and KyPlot 5.0 software. 


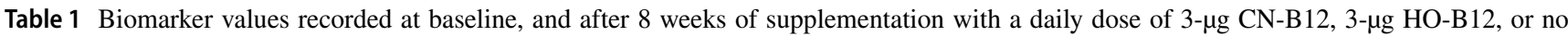
supplementation (placebo)

\begin{tabular}{|c|c|c|c|c|c|c|c|}
\hline \multirow{3}{*}{ Age (years) } & \multirow{3}{*}{$\begin{array}{l}\text { Ref. Int. } \\
-\end{array}$} & \multirow{2}{*}{\multicolumn{2}{|c|}{$\frac{\mathrm{CN}-\mathrm{B} 12 n=15(10 \text { females })}{31(22-42)}$}} & \multirow{2}{*}{\multicolumn{2}{|c|}{$\frac{\text { HO-B12 } n=16(10 \text { females })}{31(22-50)}$}} & \multirow{2}{*}{\multicolumn{2}{|c|}{$\frac{\text { Placebo } n=20(13 \text { females })}{29(21-48)}$}} \\
\hline & & & & & & & \\
\hline & & Baseline & 8 weeks & Baseline & 8 weeks & Baseline & 8 weeks \\
\hline $4 \mathrm{cB} 12$ & -0.5 to 1.5 & $\begin{array}{l}-1.6(-1.1 \text { to } \\
-3.0)\end{array}$ & $\begin{array}{l}-1.3(-0.6 \text { to } \\
-2.7)\end{array}$ & $\begin{array}{l}-1.7(-0.8 \text { to } \\
-2.9)\end{array}$ & $\begin{array}{l}-1.7(-0.3 \text { to } \\
-2.6)\end{array}$ & $\begin{array}{l}-1.7(-0.6 \text { to } \\
-3)\end{array}$ & $\begin{array}{l}-2.0(-0.7 \text { to } \\
-2.9)\end{array}$ \\
\hline $\mathrm{Cbl}(\mathrm{pmol} / \mathrm{L})$ & $200-600$ & $133(68-171)$ & $172 *(99-262)$ & $127(68-191)$ & $155 *(87-302)$ & $124(68-190)$ & $116(85-191)$ \\
\hline $\begin{array}{l}\text { HoloTC } \\
\qquad(\mathrm{pmol} / \mathrm{L})\end{array}$ & $40-150$ & $18(7-30)$ & $20 *(8-45)$ & $16(8-41)$ & $19 *(9-41)$ & $16(6-27)$ & $14 *(7-25)$ \\
\hline $\begin{array}{l}\text { TotalTC } \\
(\mathrm{pmol} / \mathrm{L})\end{array}$ & $600-1500$ & $805(605-1190)$ & $780(630-1260)$ & $890(700-1235)$ & $900(670-1080)$ & $878(610-1370)$ & $855(625-1275)$ \\
\hline $\begin{array}{l}\text { TotalHC } \\
(\mathrm{pmol} / \mathrm{L})\end{array}$ & $240-680$ & $720(540-2370)$ & $570 *(420-900)$ & 750 (495-975) & $600 *(450-855)$ & $788(390-1350)$ & $510 *(360-855)$ \\
\hline $\begin{array}{l}\mathrm{HC}-\mathrm{B} 12 \\
(\mathrm{pmol} / \mathrm{L})\end{array}$ & $60-400$ & $115(61-148)$ & $153 *(87-240)$ & $108(54-175)$ & $136 *(74-278)$ & $107(56-173)$ & $106 *(74-174)$ \\
\hline MMA $(\mu \mathrm{mol} / \mathrm{L})$ & $0.1-0.3$ & $0.8(0.5-1.6)$ & $0.7(0.2-1.7)$ & $1.2(0.3-1.7)$ & $0.9 *(0.2-1.6)$ & $0.8(0.3-1.6)$ & $0.7(0.3-1.6)$ \\
\hline $\begin{array}{l}\text { Hcy }(\mathrm{m}) \\
\quad(\mu \mathrm{mol} / \mathrm{L})\end{array}$ & $6.3-15.7$ & $14.9(13.3-35.8)$ & $16.7(12.9-39)$ & $50.3(12.3-86.8)$ & $34.7(18.3-74.8)$ & $29.6(9.6-94.5)$ & $41.4(13.4-116)$ \\
\hline Hcy (f) $(\mu \mathrm{mol} / \mathrm{L})$ & $4.9-14.9$ & $17.9(10-100)$ & $16.0 *(2.6-96.8)$ & $14.7(8.5-39.3)$ & $13.6(9.2-38.3)$ & $14.2(9.1-39.7)$ & $17.0(7.8-33-3)$ \\
\hline $\begin{array}{l}\text { Crea }(\mathrm{m}) \\
(\mu \mathrm{mol} / \mathrm{L})\end{array}$ & $60-105$ & $96(72-107)$ & - & $89(68-100)$ & - & $80(74-101)$ & - \\
\hline Crea (f) $(\mu \mathrm{mol} / \mathrm{L})$ & $45-90$ & $76(70-98)$ & - & $74(57-91)$ & - & $73(68-80)$ & - \\
\hline $\begin{array}{l}\mathrm{Hb}(\mathrm{m}) \\
\quad(\mathrm{mmol} / \mathrm{L})\end{array}$ & $8.1-10.3$ & $9.1(8.2-9.8)$ & - & $9.5(8.3-10.2)$ & - & $9.2(7.6-9.6)$ & - \\
\hline $\mathrm{Hb}(\mathrm{f})(\mathrm{mmol} / \mathrm{L})$ & $7.1-9.3$ & $7.8(6.1-9.6)$ & - & $7.6(6.8-7.1)$ & - & $8.1(5.8-8.9)$ & - \\
\hline MCV (fL) & $82-98$ & $86(77-86)$ & - & $86(67-115)$ & - & $86(67-115)$ & - \\
\hline
\end{tabular}

Median with (range) is indicated. Reference intervals are from [15, 17-22]. No statistical difference in any parameter was found between the three groups at baseline (unpaired $t$ test). The findings of low serum Cbl and holoTC concentrations combined with high MMA and Hcy concentrations confirm that the population has a low baseline B12 status, which is also supported by a combined indicator of B12 status $4 \mathrm{cB} 12$. Statistical differences $(p \leq 0.05)$ between baseline and after 8 weeks of treatment (paired $t$ test) are denoted with asterisks. Serum Cbl, holoTC, and HC-B12 increased in response to the treatment with CN-B12 and HO-B12, and a small decline was observed for MMA in the HO-group, $p=0.02)$. Crea, $\mathrm{Hb}$, and MCV were only measured at baseline. Results of Hcy, crea, and Hb were separated by males (m) and females (f)

$4 c B 12$ combined indicator of B12 status; $C b l$ cobalamin; holoTC holotranscobalamin; totalTC total transcobalamin; totalHC total haptocorrin; $H C-B 12 \mathrm{~B} 12$ bound to haptocorrin, calculated as total serum $\mathrm{Cbl}$ minus holoTC; MMA methylmalonic acid; Hcy homocysteine; crea creatinine; $\mathrm{Hb}$ hemoglobin; $\mathrm{MCV}$ red blood cell mean volume

\section{Results}

\section{Characteristics of the study population}

Indian participants $(n=60)$ with pre-study serum $\mathrm{Cbl}$ below $150 \mathrm{pmol} / \mathrm{L}$ (measured 2 weeks prior to enrollment) were divided into three groups: the CN-group (CN-B12 supplementation), the HO-group (HO-B12 supplementation), and the placebo group (no B12 supplementation). The median (range) age of the participants (27 males and 33 females) was 30 [21-50] years. Six participants dropped out of the study right after inclusion; four from the $\mathrm{CN}$-group and two from the HO-group. One participant from the placebo group dropped out after 6 weeks of treatment, but the collected data from the first 6 weeks were included in the study. One participant in the HO-group presented extreme values at baseline (serum Cbl: 72 pmol/L; holoTC: 4 pmol/L; MMA: $5.4 \mu \mathrm{mol} / \mathrm{L}$; Hcy: $116 \mu \mathrm{mol} / \mathrm{L})$. He was excluded from the final data set, but his biomarker values are presented in Supplementary Data S2. Finally, we excluded two participants (one from the $\mathrm{CN}$-group and one from the HOgroup) with baseline serum $\mathrm{Cbl}$ levels well above the lower limit (200 pmol/L) of the reference interval [19] (240 and $340 \mathrm{pmol} / \mathrm{L}$, respectively).

The baseline characteristics of the three groups (Table 1) did not differ, and all showed metabolic signs of B12 deficiency. All baseline values of the markers (serum Cbl, holoTC, MMA, Hcy) deviated considerably from the reference intervals in Western populations. The combined indicator of B12 status $(4 \mathrm{cB} 12=[$ median (range) $]-1.65(-0.64$ to $-4.07)$ ] corresponded to the overall score of deficiency $-2 \pm 0.5$ (classified as possible B12 deficiency) [18]. Two 

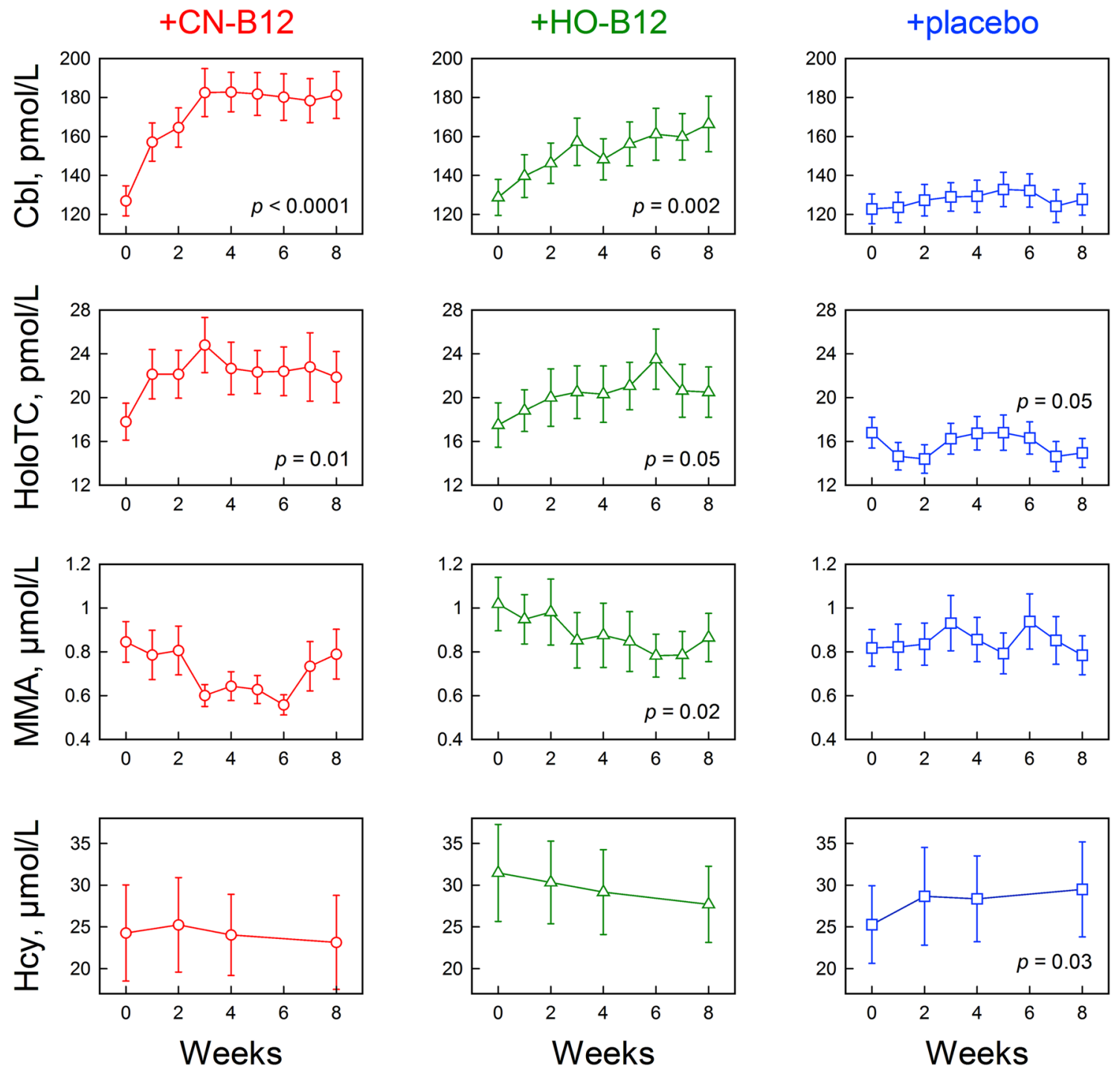

Fig. 1 Changes in markers of B12 status in response to low-dose B12 supplementation. Indian adults with low B12 status received

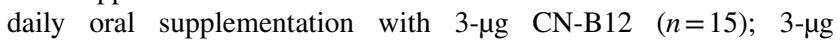
HO-B12 $(n=16)$; or placebo $(n=20)$ for 8 weeks. Absolute serum concentrations of cobalamin ( $\mathrm{Cbl})$, holotranscobalamin (holoTC),

participants showed extremely high levels of Hcy $\geq 100 \mu \mathrm{M}$, which may be the result of a joint B12 and folate deficiency (folate not measured).

The baseline correlations showed that (1) serum $\mathrm{Cbl}$ was strongly inversely correlated to both MMA $(r=-0.42$, $p=0.002)$ and Hcy $(r=-0.55, p<0.0001)$; (2) MMA and Hcy were related to each other $(r=0.31, p=0.03)$; (3) MCV was related to Hcy $(r=0.40, p=0.004)$, but not to serum $\mathrm{Cbl}$ or MMA concentrations.

The baseline concentration of totalHC (Table 1) is above reference intervals (determined for a Scandinavian population [17]); but at the same level of a comparable Indian population with low B12 status [14]. methylmalonic acid (MMA), and homocysteine (Hcy) are shown $($ mean \pm SE). Statistical differences between baseline and week 8 are indicated (paired $t$ test). $p$ values $\leq 0.05$ were accepted as statistically significant. The figure is made in KyPlot version 5.0

\section{Effect of intervention}

The participants received one daily dose of $3-\mu \mathrm{g} \mathrm{CN}-\mathrm{B} 12$ (CN-group), 3- $\mu$ g HO-B12 (HO-group), or no supplementation (placebo group) for 8 weeks. Figure 1 shows the absolute measurements of the biomarkers of B12 status at each time point, and Fig. 2 shows the model approximations of the normalized changes expressed as differences from the baseline for serum $\mathrm{Cbl}$ and holoTC (Fig. 2a, b) or ratios to the baseline for MMA and Hcy (Fig. 2c, d), as explained in the method section and in the Supplementary Data S1. The participants with high baseline MMA and Hcy showed a larger decrease in metabolite concentration in response to 
A (o) $\mathrm{CN}-\mathrm{B} 12 \neq(\Delta) \mathrm{HO}-\mathrm{B} 12 \neq(\square)$ placebo

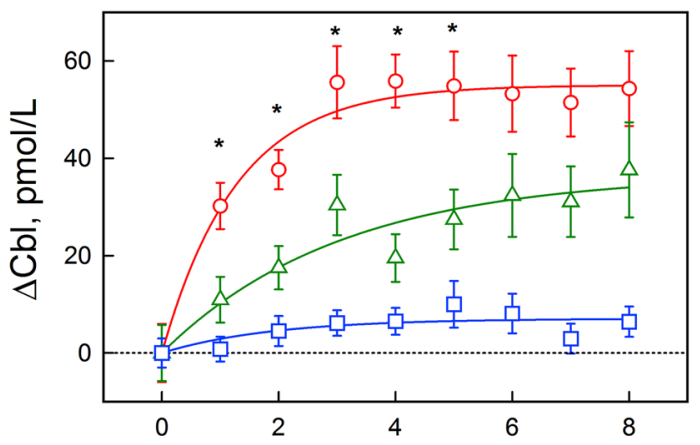

C $(\mathrm{o}) \mathrm{CN}-\mathrm{B} 12=(\Delta) \mathrm{HO}-\mathrm{B} 12 \neq(\square)$ placebo

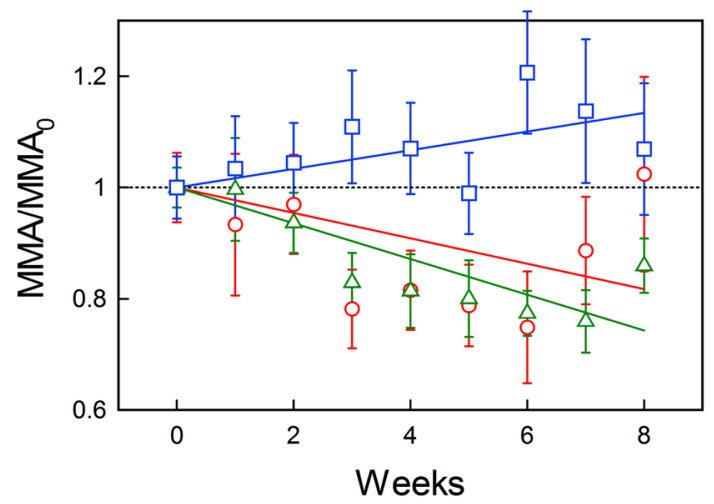

Fig. 2 Normalized effect of CN-B12 and HO-B12 supplementation (adjusted for baseline). Change in a serum cobalamin ( $\Delta \mathrm{Cbl})$ and $\mathbf{b}$ holotranscobalamin ( $\Delta$ holoTC); relative change in $\mathbf{c}$ methylmalonic acid $\left(\mathrm{MMA} / \mathrm{MMA}_{0}\right)$ and $\mathbf{d}$ homocysteine $\left(\mathrm{Hcy} / \mathrm{Hcy}_{0}\right)$. Statistical difference between the $\mathrm{CN}$-group and the HO-group at each individual time point is indicated with an asterisk (unpaired $t$ test). The experimental points are presented as means \pm SE for treatments with

B12 supplementation when compared with the participants with lower baseline values (cut-off MMA $=0.7 \mu \mathrm{mol} / \mathrm{L}$, $p=0.003$; cut-off Hcy $=20 \mu \mathrm{mol} / \mathrm{L}, p<0.0001)$. Though not included in this calculation, this was even more obvious for the participant with highly elevated baseline levels of both MMA and Hcy (Supplementary Data S2). The observed proportionality of response to the baseline was, at least partially, compensated for using ratios (MMA/MMA ${ }_{0}$ and $\mathrm{Hcy} / \mathrm{Hcy}_{0}$ ) instead of differences.

At the first stage of analysis, each group was examined for response during the time of treatment. This comparison included a paired $t$ test of baseline (week 0 ) vs. weeks $1-8$, as well as examination of the fitting models "test" vs. "zero" (i.e., probability that all floating parameters in Eq. 1 or Eq. 2 are equal to zero, see Supplementary Data S1).

The placebo group showed no change in the absolute values of serum $\mathrm{Cbl}$ or MMA during the study period, but revealed a small decline in holoTC (from 16 to $14 \mathrm{pmol} / \mathrm{L}$; $p=0.05$ ) and a small increase in Hcy (from 25.3 to
B (o) $\mathrm{CN}-\mathrm{B} 12=(\Delta) \mathrm{HO}-\mathrm{B} 12 \neq(\square)$ placebo

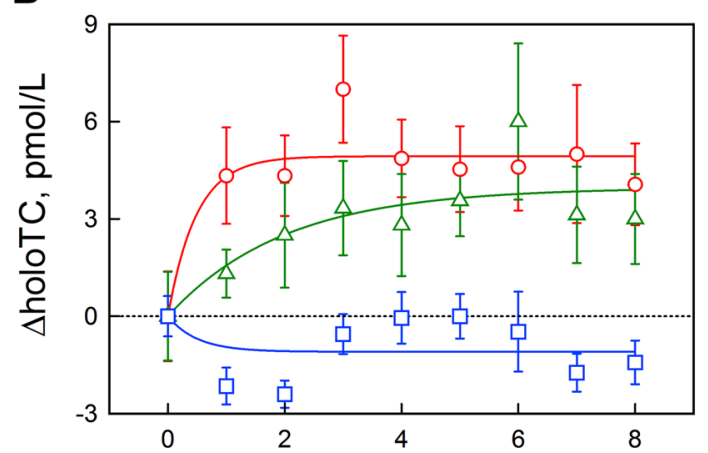

D $($ o) $\mathrm{CN}-\mathrm{B} 12=(\Delta) \mathrm{HO}-\mathrm{B} 12 \neq \approx(\square)$ placebo

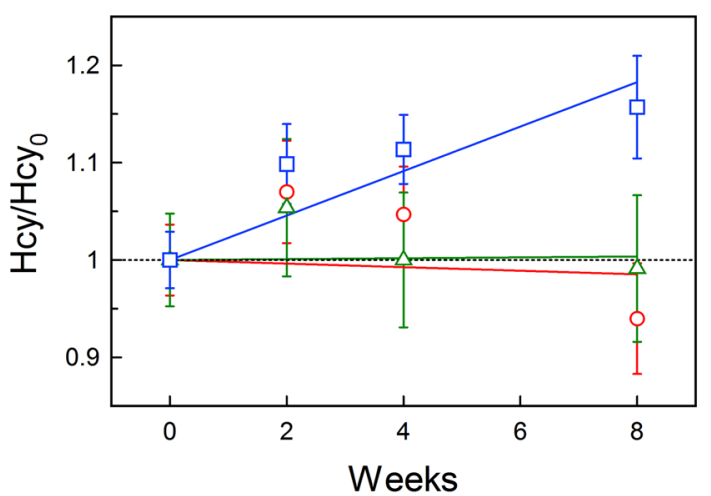

CN-B12 (circle, red), HO-B12 (triangle, green), and placebo (square, blue). The solid lines show fitting models obtained after approximation of all points available. The dotted line indicates the baseline level. The overall comparison of the models (unpaired $t$ test) is schematically shown above each subfigure; see main text and Supplementary Data S1 for the details. The figure is made in KyPlot version 5.0

$29.5 \mu \mathrm{mol} / \mathrm{L} ; p=0.03$ ), when testing week 8 vs. week 0 (Fig. 1). The model approximations of the normalized placebo data (Fig. 2, square-blue) indicated a small but detectable upward shift in $\Delta \mathrm{Cbl}(p=0.01)$. An upward drift of Hcy/ $\mathrm{Hcy}_{0}$ was also detected $\left(p=6 \times 10^{-4}\right)$. Possible decrease of $\Delta$ holoTC $(p=0.10)$ and increase of MMA/MMA $(p=0.16)$ were less convincing. It can be conjectured that the metabolic state of the placebo group has a tendency to deteriorate in terms of the overall B12 status.

The $\mathrm{CN}$-group showed an overall increase in serum $\mathrm{Cbl}$ (from 133 to $172 \mathrm{pmol} / \mathrm{L} ; p<0.0001$ ) and holoTC (from 18 to $20 \mathrm{pmol} / \mathrm{L} ; p<0.0001)$ in response to 8 weeks of supplementation (Fig. 1; Table 1). The approximating fits of $\Delta \mathrm{Cbl}$ and $\Delta$ holoTC (Fig. 2a, b, circle-red) also differed considerably from the respective "zero" models (probabilities of the latter were assessed as $p=10^{-17}$ and 0.0004 , respectively). The increasing curves apparently leveled off after 5 weeks for $\Delta \mathrm{Cbl}$ and 2 weeks for $\Delta$ holoTC (all numerical fitting coefficients are presented in Supplementary Data S1). A 
small decline in the absolute concentration of MMA was observed after 3 weeks of supplementation $(p=0.01)$, but this change was no longer significant after 8 weeks (Fig. 1). Yet, no significant difference between weeks 3 and 8 was found either. No change in the absolute concentrations of Hcy was found during the study period (Fig. 1). Figure 2c $\left(\mathrm{MMA} / \mathrm{MMA}_{0}\right)$ and Fig. $2 \mathrm{~d}\left(\mathrm{Hcy} / \mathrm{Hcy}_{0}\right)$, circle-red, show the fitted curves of normalized data. Responses to CN-B12 supplementation (i.e., linear slopes $A_{2}$ in Eq. 2, Supplementary Data S1) were either uncertain (MMA/MMA,$p=0.08$ ) or clearly absent $\left(\mathrm{Hcy} / \mathrm{Hcy}_{0}, p=0.80\right)$.

The HO-group showed an increase in both serum $\mathrm{Cbl}$ (from 126 to $154 \mathrm{pmol} / \mathrm{L} ; p=0.001$ ) and holoTC (15 to $18 \mathrm{pmol} / \mathrm{L} ; p=0.001)$ in response to the supplementation. The same tendency was exhibited in the normalized models for $\Delta \mathrm{Cbl}\left(p=10^{-6}\right)$ and $\Delta$ holoTC $(p=0.003)$. The respective functions apparently reached plateaus at the end of treatment, and the process developed somewhat faster for $\Delta$ holoTC (Fig. 2a, b, Z-green). The absolute concentrations of MMA showed a decline after 3 weeks of treatment $(p=0.04)$, and the change remained significant for the rest of the study period $(p=0.02)$, whereas no changes in Hcy were observed (Fig. 1). The normalized chart of MMA/ $\mathrm{MMA}_{0}$ showed a tendency to decline $\left(p=3 \times 10^{-5}\right)$, whereas $\mathrm{Hcy} / \mathrm{Hcy}_{0}$ apparently remained on the same level $(p=0.10)$, Fig. 2c, d, Z-green.

At the second stage of analysis, we compared the responses between the three groups. This was done by a pairwise examination of the fitting models (e.g., "CN-group" vs. "HO-group", "CN-group" vs. "placebo group", etc), where the identity of all complimentary fitting parameters between groups "A" vs. "B" was tested (see Supplementary data S1).

Both treatment groups considerably differed from the placebo group in their $\Delta \mathrm{Cbl}$ records $\left(p=10^{-10}\right.$ for $\mathrm{CN}$ group $=$ placebo group and $p=0.0009$ for HO-group $=$ placebo group) and $\Delta$ holoTC records $(p=0.0003$ for $\mathrm{CN}$ group $=$ placebo group and $p=0.003$ for HO-group $=$ placebo group), Fig. 2a, b. Treatment groups also differed from each other in $\Delta \mathrm{Cbl}$. For example, the $\mathrm{CN}$-group showed both a steeper increase in $\Delta \mathrm{Cbl}$ and a higher plateau level compared with the HO-group ( $p=0.01$ for CN-group $=\mathrm{HO}$-group), Fig. 2a. The two treatment models apparently did not differ in $\Delta$ holoTC ( $p=0.34$ for $\mathrm{CN}$-group $=\mathrm{HO}$-group). The fraction of total $\mathrm{Cbl}$ attached to $\mathrm{HC}$ ( $\mathrm{HC}-\mathrm{Cbl})$ increased similar to the total $\mathrm{Cbl}$ in $\mathrm{CN}$ - and HO-groups (data not shown).

The normalized records of MMA/MMA $\mathrm{M}_{0}$ demonstrated very similar linear slopes over time for both vitamin forms $(p=0.54$ for $\mathrm{CN}$-group $=\mathrm{HO}$-group $)$, which differed from the placebo group $(p=0.03$ for $\mathrm{CN}$-group $=$ placebo group and $p=0.0006$ for HO-group $=$ placebo group). It should be noted in this regard that the combination of an "insignificant" upward drift in the placebo group with an "insignificant" downward drift of the $\mathrm{CN}$-group provided a "significant" difference between the two records of MMA/ $\mathrm{MMA}_{0}$ (Fig. 2c, square-blue vs. circle-red). Disregarding the apparently unchanging level of $\mathrm{Hcy} / \mathrm{Hcy}_{0}$ in both treatment groups, both variants of the vitamin supplementation apparently differed from the upward-tending placebo group ( $p=0.02$ for $\mathrm{CN}$-group $=$ placebo group and $p=0.06$ for HOgroup $=$ placebo group).

No major differences were observed between males and females (data not shown).

\section{Discussion}

Here, we investigate and compare the effect of supplementation with one daily oral dose $(3-\mu \mathrm{g})$ of CN-B12 (used in vitamin pills) or HO-B12 (found in food items) for 8 weeks on the B12 status in a nutritionally B12-deficient Indian population. We report two major findings: (1) supplementing with $\mathrm{CN}-\mathrm{B} 12$ increases serum $\mathrm{Cbl}$ more than HO-B12, but the metabolic parameters of $\mathrm{B} 12$ status respond similar to both treatments; (2) supplementing for 8 weeks with $3-\mu \mathrm{g}$ B 12 per day causes only minor improvements in the metabolites, with slightly decreasing MMA and stabilizing Hcy concentrations.

Our study has some limitations. The number of participants was relatively small and the duration of the trial was only 8 weeks. For this reason, we cannot conclude on the effect of long-term treatment with low doses of CN-B12 and HO-B12. We did not test if our participants could absorb B12 prior to the study. However, based on the increase in holoTC and/or plasma B12 in response to treatment with HO-B12 and CN-B12, the participants were judged able to absorb B12. Despite these limitations, the study provides a proof-of-concept and stresses that larger long-term intervention studies are needed to evaluate if treatment with low doses of B12 can rescue a nutritionally induced low B12 status.

Currently, CN-B12 is the preferable form for oral use in vitamin pills, fortification, and pharmacological preparations. The rational is that this form of the vitamin is both chemically stable and cheap. In agreement with the previous studies [11-14], we find that $\mathrm{CN}-\mathrm{B} 12$ induces a higher increase in the circulating total $\mathrm{Cbl}$ in comparison to HO-B12. Interestingly, administration of HO-B12 is as efficient-if not slightly better-in improving other markers of an impaired B12 status, notably MMA. This result is in accord with our previous studies in rats $[12,13]$. Thus, based on our present data, we conclude that the increase in serum $\mathrm{Cbl}$ upon administration of CN-B12 does not mirror a superior effect of this vitamin form, but rather shows that $\mathrm{CN}-\mathrm{B} 12$ has a tendency to fall behind HO-B12 in the rates of tissue uptake. Further studies are warranted to prove whether HO-B12 is even superior to CN-B12 in its biological effect. 
In agreement with the previous works [6, 7, 24], we report that supplementation with $3 \mu \mathrm{g}$ of either CN-B12 or HO-B12 for 8 weeks caused a minor improvement in biomarkers of B12 status. We observed a gradually reached steady state in serum $\mathrm{Cbl}$ (after 5-8 weeks of treatment) and holoTC (after 2-6 weeks) and only marginal changes in MMA and Hcy. However, at the end of the study, concentrations of all markers were still far below (serum $\mathrm{Cbl}$ and holoTC) and far above (MMA and Hcy) the reference intervals for Western populations. Two previous intervention studies were conducted in comparable populations from the same geographical region in India and showed similar results. Naik et al. [6] found that low doses of B12 (2.5-3- $\mu \mathrm{g} /$ day) (supplied for 2 weeks in buffalo milk increased plasma concentrations of $\mathrm{Cbl}$ and reduced concentrations of Hcy after 2 weeks of treatment, without reaching reference intervals. Yajnik et al. [7] found the same result when orally supplementing methyl$\mathrm{B} 12$ as high as $500 \mu \mathrm{g} /$ day for a period of 6 weeks. In the latter study, a plateau of 13- $\mu \mathrm{mol} / \mathrm{L}$ Hcy was reached after 2 weeks of treatment. No further changes occurred within the next 4 weeks of treatment, and neither plasma $\mathrm{Cbl}$ nor Hcy reached the accepted reference levels within the 6 weeks of study. The authors rightfully speculated that the findings could be explained by saturation of the absorption system, giving a balance between the absorption rate and the tissue clearance disregarding the excessive dose of B12. Furthermore, Rajan et al. [24] found that a daily dose of 25 and 100$\mu \mathrm{g}$ B12 could not normalize MMA and Hcy within 6 weeks in a population of B12-deficient elderly. On the other hand, Rajan et al. [24] and Morkbak et al. [25] both demonstrated that high pharmacological doses of B12 (above $1000 \mu \mathrm{g} /$ day) normalized the levels of Hcy or MMA within 4-6 weeks in B12-deficient elderly and vegans, respectively. Altogether, our data and the previous intervention studies [6, 7, 24, 25] indicate that the daily dose of B12 supplementation needs to contain quantities far above the RDA of $2.4-\mu \mathrm{g} / \mathrm{day}$, to restore the optimal biomarkers of B12 status in individuals with a low B12 status due to inadequate intake. An alternative would be a more frequent supplementation with lowdose B12. In this regard, our recent study on acute uptake of B12 [14] showed that supplementation with three doses of $3 \mu \mathrm{g} /$ day of CN-B12/HO-B12 for 2 days caused at least a ninefold increase in holoTC [median (range)] [CN-B12: $\Delta$ holoTC $=23(0-55) \mathrm{pmol} / \mathrm{L}, n=20 ; \mathrm{HO}-\mathrm{B} 12: \Delta$ holoTC $=7$ ( -10 to 29 ) pmol/L; $n=19$ ], vs. 1 week of treatment with one dose of $3 \mu \mathrm{g} /$ day CN-B12/HO-B12 (this study; baseline vs. week 1) (CN-B12: $\Delta$ holoTC $=2.5[-3$ to 18$] \mathrm{pmol} / \mathrm{L}$, $n=20$; HO-B12: $\Delta$ holoTC $=0.5$ [ -3 to 7] $\mathrm{pmol} / \mathrm{L}, n=20$ ).

An interesting finding of the present study is that the plasma concentrations of both MMA and Hcy apparently decrease after a lag period of 2-4 weeks, respectively, following administration of a low physiological dose of oral B12 on daily basis (Figs. 1, 2). Notably, in these lag periods, 60-70\% of the participants showed a decrease in MMA and 30-35\% in Hcy, whereas the rest belonged to "non-responders". The number of participants responsive to treatment increased to 70-90\% (MMA) and 50-70\% (Hcy) during the following weeks. In other words, the treatment groups apparently separate into fast responders (showing a noticeable change soon after the beginning of treatment) and slow responders (showing a lag). This fact presents some difficulty in the description of metabolites vs. time by a specific mathematical function, e.g., exponent, line, sigmoid, etc. In the absence of more firm evidence, a linear approximation of the ratio records was used here (Fig. 2c, d). Another interesting fact concerns a single individual with high baseline levels of the metabolic markers. This participant showed the best initial response in Hcy, which was, however, not mirrored in MMA (Supplementary Data S2). The latter metabolite started to decrease only after a lag of 2 weeks. The biological rationale of such difference might imply slower accumulation of the cofactor in mitochondria (MMA reaction) in comparison to the cytoplasm (Hcy reaction). The previous studies have shown that high doses of injected B12 decreased MMA within a few days [26]. We speculate that the time of response might be dose-dependent, so that higher doses of B12 or/and frequent administration will shorten the lag period.

One study, apparently conflicting with the aforementioned studies and their conclusions should, however, be mentioned. Deshmukh et al. [27] observed a marked effect of 4-month treatment with 2- $\mu$ g B12/day, which decreased Hcy in an Indian population to the values within the reference interval. Our population had lower baseline serum Cbl (128 pmol/L), but similar Hcy $(18.1 \mu \mathrm{mol} / \mathrm{L})$ in comparison to the Deshmukh population (Cbl; $166 \mathrm{pmol} / \mathrm{L}$; Hcy: $18.6 \mu \mathrm{mol} / \mathrm{L})$. We found almost no change in Hcy after 1.5 month of treatment, which could indicate that the response of metabolites to low doses of $\mathrm{Cbl}$ might be a sigmoid function with a pronounced lag period followed by a rather steep return to the normal level. Alternatively, the undetected "insignificant" changes (tested after a relatively short treatment period) can gradually lead to a final "significant" alteration of the metabolic balance. Further work is needed to address this issue.

In conclusion, we have demonstrated that 8 weeks of daily oral treatment with $3-\mu \mathrm{g}$ CN-B12 or 3- $\mu$ g HO-B12 causes an increase in total serum $\mathrm{Cbl}$ and holoTC, plus minor changes in the metabolic markers MMA and Hcy. Our findings show that the current RDA is insufficient for a short-term restoration of an impaired B12 status. Future studies are requested to establish the dose of $\mathrm{B} 12$ needed to restore an impaired B12 status. A benefit of HO-B12 vs. CN-B12 administration was suggested, but not definitively proven. Further studies should be directed to explore the dose and the form of B12 requested to restore and maintain an optimal B12 status in populations with low dietary intake of this vitamin. 
Acknowledgements The work is part of the IMPROVIT project (http:// www.improvit-project.com) financed by the Department of Biotechnology, Ministry of Science \& Technology, Government of India [Grant No. BT/IN/Denmark/06/SSN/2015 (No. 83-85)], and Innovation Fund Denmark (Grant No. 4096-00003B). The authors would like to thank Inger Marie Jensen and Jette Fisker Pedersen, Department of Clinical Biochemistry, Aarhus University Hospital, for the excellent technical assistance, and Torben Ellebaek Petersen for the helpful discussions. Authors would also like to thank Swati, Swapnali, Sandeep, Mini, and Vandana, Department of Clinical Biochemisty, Deenanath Mangeshkar Hospital and Research Center. The authors are grateful to Dr. Dhananjay Kelkar, Medical Director, Deenanath Mangeshkar Hospital, and Research Center for his keen interest and advice.

\section{Compliance with ethical standards}

Ethical approval The study was performed within the confines of the Helsinki Declaration II, and the study was approved by the Institutional Ethics Committee of Deenanath Mangeshkar Hospital and Research Center (Project no. 2015_APR_SN_167). All individuals gave their informed consent before inclusion in the study.

Conflict of interest The authors declare that they have no conflict of interest.

Open Access This article is distributed under the terms of the Creative Commons Attribution 4.0 International License (http://creativecommons.org/licenses/by/4.0/), which permits unrestricted use, distribution, and reproduction in any medium, provided you give appropriate credit to the original author(s) and the source, provide a link to the Creative Commons license, and indicate if changes were made.

\section{References}

1. Farquharson J, Adams JF (1976) The forms of vitamin B12 in foods. Br J Nutr 36:127-136

2. Pratt JM, Williams RJ (1961) The spectra and structure of the cobalamins. Biochim Biophys Acta 46:191-192

3. Vogiatzoglou A, Smith AD, Nurk E, Berstad P, Drevon CA, Ueland PM, Vollset SE, Tell GS, Refsum H (2009) Dietary sources of vitamin B-12 and their associations with plasma vitamin B-12 concentrations in the general population: the Hordaland Homocysteine Study. Am J Clin Nutr 89:1078-1087

4. Tucker KL, Rich S, Rosenberg I, Jacques P, Dallal G, Wilson PW, Selhub J (2000) Plasma vitamin B-12 concentrations relate to intake source in the Framimgham Offspring study. Am J Clin Nutr 71:514-522

5. Institute of Medicine (US) Standing Committee on the Scientific Evaluation of Dietary Reference Intakes and its Panel on Folate, Other B Vitamins, and Choline (1998) Dietary Reference Intakes for Thiamin, Riboflavin, Niacin, Vitamin B6, Folate, Vitamin B12, Pantothenic acid, Biotin, and Choline. National Academic Press, Washington

6. Naik S, Bhide V, Babhulkar A, Mahalle N, Parab S, Thakre R, Kulkarni M (2013) Daily milk intake improves vitamin B-12 status in young vegetarian Indians: an intervention trial. Nutr J 12:136

7. Yajnik CS, Lubree HG, Thuse NV, Ramdas LV, Deshpande SS, Deshpande VU, Despande JA et al (2007) Oral vitamin B12 supplementation reduces plasma total homocysteine concentration in women in India. Asia Pac J Clin Nutr 16:103-109

8. Swaminathan S, Thomas T, Kurpad AV (2015) B-vitamin interventions for women and children in low-income populations. Curr Opin Clin Nutr Metab Care 18:295-306
9. Weisberg H, Glass JGB (1966) Hydroxocobalamin. VI. Comparison of intestinal absorption in man of large doses of hydroxocobalamin and cyanocobalamin. Proc Soc Exp Biol Med 122:25-28

10. Adams JF, Ross SK, Mervyn L, Boddy K, King P (1971) Absorption of cyanocobalamin, coenzyme B12, methylcobalamin, and hydroxocobalamin at different dose levels. Scand J Gastroenterol 6:249-252

11. Heinrich HC, Gabbe EE (1964) Metabolism of the vitamin B12-coenzyme in rats and man. Ann N Y Acad Sci 112:871-903

12. Kornerup LS, Juul CB, Fedosov SN, Heegaard CW, Greibe E, Nexo E (2015) Absorption and retention of free and milk protein-bound cyano- and hydroxocobalamins. An experimental study in rats. Biochimie 126:57-62

13. Kornerup LS, Fedosov SN, Juul CB, Greibe E, Heegaard CW, Nexo E (2017) Tissue distribution of oral vitamin B12 is influenced by B12 status and B12 form: an experimental study in rats. Eur J Nutr. https://doi.org/10.1007/s00394-017-1424-0

14. Greibe E, Mahalle N, Bhide V, Heegaard CW, Naik S, Nexo E (2017) Increase in circulating holotranscobalamin after oral administration of cyanocobalamin or hydroxocobalamin in healthy adults with low and normal cobalamin status. Eur J Nutr. https://doi. org/10.1007/s00394-017-1553-5

15. Nexo E, Christensen AL, Hvas AM, Petersen TE, Fedosov SN (2002) Quantification of holotranscobalamin, a marker of vitamin B12 deficiency. Clin Chem 48:561-562

16. Morkbak AL, Heimdal RM, Emmens K, Molloy A, Hvas AM, Schneede J, Clarke R et al (2005) Evaluation of the technical performance of novel transcobalamin (holoTC) assay in a multicenter European demonstration project. Clin Chem Lab Med 43:1058-1064

17. Morkbak AL, Pedersen JF, Nexo E (2005) Glycosylation independent measurement of the cobalamin binding protein haptocorrin. Clin Chim Acta 356:184-190

18. Fedosov SN, Brito A, Miller JW, Green R, Allen LH (2015) Combined indicator of vitamin B12 status: modification for missing biomarkers and folate status and recommendations for revised cutpoints. Clin Chem Lab Med 53:1215-1225

19. Nexo E (1983) Variation with age of reference values for p-cobalamins. Scand J Haematol 30:430-432

20. Rasmussen Rasmussen K, Moller J, Lyngbak M, Pedersen AM, Dybkjaer L (1996) Age- and gender-specific reference intervals for total homocysteine and methylmalonic acid in plasma before and after vitamin supplementation. Clin Chem 42:630-636

21. Rustad Rustad G, Felding P, Franzson L, Kairisto V, Lahti A, Martensson A, Hyltolf PP et al (2004) The Nordic Reference Interval Project 2000: recommended reference intervals for 25 common biochemical properties. Scand J Clin Lab Inves 64:271-284

22. Nordin Nordin G, Martensson A, Swolin B, Sandberg S, Christensen NJ, Thorsteinsson V, Franzson L, Kairisto V, Savolainen ER (2004) A multicentre study of reference intervals for haemoglobin, basic blood cell counts and erythrocyte indices in the adult population of the Nordic countries. Scand J Clin Lab Invest 64:385-398

23. Fedosov SN (2010) Metabolic signs of vitamin B(12) deficiency in humans: computational model and its implications for diagnostics. Metabolism 59:1124-1138

24. Rajan S, Wallace JI, Brodkin KI, Beresford SA, Allen RH, Stabler SP (2002) Response of elevated methylmalonic acid to three dose levels of oral cobalamin in older adults. J Am Geriatr Soc 50:1789-1795

25. Morkbak AL, Hvas AM, Lloyd-Wright Z, Sanders TA, Bleie O, Refsum H, Nygaard OK, Nexo E (2006) Effect of vitamin B12 treatment on haptocorrin. Clin Chem 52:1104-1111

26. Rasmussen K, Moller J, Ostergaard K, Kristensen MO, Jensen J (1990) Methylmalonic acid concentrations in serum of normal subjects: biological variability and effect of oral L-isoleucine loads before and after intramuscular administration of cobalamin. Clin Chem 36:1295-1299 
27. Deshmukh US, Joglekar CV, Lubree HG, Ramdas LV, Bhat DS, Naik SS, Hardikar PS et al (2010) Effect of physiological doses of oral vitamin B12 on plasma homocysteine: a randomized, placebocontrolled double-blinded trial in India. Eur J Clin Nutr 64:495-502 